\title{
Responsabilidad Social Empresarial para el desarrollo de la competitividad farmacéutica
}

\section{Corporate Social Responsibility for the development of pharmaceutical competitiveness}

\author{
José Humberto Picón-Lucero \\ jose.picon@psg.ucacue.edu.ec \\ Universidad Católica de Cuenca, Cuenca \\ Ecuador \\ https://orcid.org/0000-0001-8610-2005 \\ Moisés Marcelo Matovelle-Romo \\ mmmatoveller@ucacue.edu.ec \\ Universidad Católica de Cuenca, Cuenca \\ Ecuador \\ https://orcid.org/0000-0002-6260-6644 \\ Flor Isabel Salazar-Vázquez \\ fisalazarv@ucacue.edu.ec \\ Universidad Católica de Cuenca, Cuenca \\ Ecuador \\ https://orcid.org/0000-0002-0071-0139 \\ Ana Luisa-del-Rocío Ordoñez-Laso \\ alordonesl@ucacue.edu.ec \\ Universidad Católica de Cuenca, Cuenca \\ Ecuador \\ https://orcid.org/0000-0002-7935-6709
}

Recibido: 20 de mayo de 2020

Revisado: 15 de junio de 2020

Aprobado: 30 de julio de 2020

Publicado: 15 de agosto de 2020 


\title{
RESUMEN
}

El objetivo de la investigación fue analizar la Responsabilidad Social Empresarial para el desarrollo de la competitividad farmacéutica de la ciudad de Cuenca - Ecuador. De tipo descriptiva con diseño de campo no experimental la muestra poblacional estuvo constituida por 280 personas ligadas al sector farmacéutico. El 58,21\% de encuestados admite que existe un descuido en realizar actividades que permita vincular a la farmacia con la comunidad. Las farmacias juegan un rol muy importante dentro de la sociedad, siendo un vínculo directo entre los centros médicos y sus pacientes, están inmersas en pocas actividades de responsabilidad social, pero que no fueron consideradas como tal. El campo de acción para implementar la RSE, es amplio y van desde actividades de pronta ejecución hasta las que nos conlleva mayor tiempo de planificación, el implementar las acciones sugeridas, permitirá mejorar su legitimidad y ganar mayor confianza, aportando de forma efectiva a todos los stakeholders.

Descriptores: Microeconomía; oferta y demanda; política social; responsabilidad social. (Palabras tomadas del Tesauro UNESCO).

\begin{abstract}
The objective of the research was to analyze the Corporate Social Responsibility for the development of pharmaceutical competitiveness of the city of Cuenca - Ecuador. Descriptive with a non-experimental field design, the population sample consisted of 280 people linked to the pharmaceutical sector. $58.21 \%$ of respondents admit that there is a neglect in carrying out activities that allow linking the pharmacy with the community. Pharmacies play a very important role within society, being a direct link between medical centers and their patients, they are immersed in few activities of social responsibility, but they were not considered as such. The field of action to implement CSR is broad and ranges from promptly executed activities to those that take us longer to plan. Implementing the suggested actions will improve its legitimacy and gain greater confidence, effectively contributing to all stakeholders. stakeholders.
\end{abstract}

Descriptors: Microeconomics; supply and demand; social policy; social responsibility. (Words taken from the UNESCO Thesaurus). 
Revista Arbitrada Interdisciplinaria KOINONIA

Año 2020. Vol V. N³. Especial: Administración

Hecho el depósito de Ley: FA2016000010 ISSN: $2542-3088$

FUNDACIÓN KOINONIA (F.K). Santa Ana de Coro. Venezuela.

José Humberto Picón-Lucero; Moisés Marcelo Matovelle-Romo; Flor Isabel Salazar-Vásquez

Ana Luisa del Rocío Ordoñez-Laso

\section{INTRODUCCIÓN}

La salud en tiempos actuales se define, como un estado integral de bienestar, tomando en cuenta todos los aspectos del ser humano físico, mental y social, reemplazando a lo que se conocía antiguamente como la ausencia de enfermedad o incapacidad (AlcántaraMoreno, 2008). La necesidad de buscar una cura a las enfermedades es tan antigua como la aparición del humano, este al encontrarse en situaciones de climas adversos, ataque de animales, o lucha con otros humanos ve alterado el normal funcionamiento de su cuerpo; Un médico primitivo fue al mismo tiempo un herbolario y farmacéutico sin tan siquiera aún estar definidos esos términos, al mismo tiempo, tenía que saber distinguir, diagnosticar una enfermedad y saber que aplicar como tratamiento de mejora (CoronelCarbo \& Marzo-Páez, 2017).

Analizando la trayectoria de la medicina en nuestro territorio, (Muñoz, 1952) en su investigación de datos históricos galénicos en Ecuador, pudo encontrar que los primeros registros se encuentran contenidos en el texto denominado "Relaciones de la Ciudad de San Francisco de Quito"; Escrito en 1573, en el mismo ya se indica de forma empírica por improvisados farmaceutas, el uso en píldoras de la zarzaparrilla para curar sífilis. Con estos datos encontramos una estrecha relación de la medicina y la rama farmacéutica, (Tafur-Valderrama \& García-Jiménez, 2006) Indican que el objetivo mayor de la atención farmacéuticas es mejorar la calidad de vida en cuanto a la salud de los ciudadanos.

En ese contexto para una mejor atención a la ciudadanía, la Agencia Nacional de Regulación, Control y Vigilancia Sanitaria (ARCSA) divide al país en nueve zonas, en nuestro caso nos encontramos en la zona 6 que abarca Azuay, Cañar y Morona Santiago. Dentro de Azuay tenemos al cantón Cuenca que se divide en dos distritos que abarca 23 circuitos y tiene un total de 467 Farmacias (Arcsa, 2020).

Por tanto, se evidencia que las farmacias cubren la demanda poblacional, juegan un papel esencial en la sociedad y está en constante mejora; sin embargo, recibe continuamente opiniones negativas a su gestión, pues la percepción de la comunidad es 
que anteponen sus intereses a la supervivencia de los ciudadanos (Porter \& Kramer, 2006). Por ello autores como (Kermani, 2004) han indicado su preocupación por la imagen venida a menos de las farmacias en relación de Responsabilidad Social Empresarial (RSE).

En consecuencia, considerando que en los últimos años se tiene mayor interés por prácticas de RSE dentro de las empresas (Cuadrado, et al., 2014), las farmacias deben tener mayor sensibilidad para atender las solicitudes de los grupos de interés o stakeholders, encontrando formas para mantener una cercanía que les permita mejorar su legitimidad y ganar mayor confianza (Chen, et al., 2016). Por este motivo (Del-Castillo, et al., 2011) indican la necesidad de poner en marcha en el sector una estrategia de RSE, en el que se difunda información del impacto social, medioambiental y económico en el lugar de funcionamiento. Existen varios modelos para medir la RSE, sobresaliendo los indicadores del instituto ETHOS, que divide en siete áreas 1. Valores, Transparencia, Gobernanza, 2. Público interno, 3. Medioambiente, 4. Proveedores, 5. Consumidores y Clientes, 6. Comunidad, 7. Gobierno y Sociedad.

En contexto de lo mencionado, la presente investigación tiene como objetivo, determinar que elementos de RSE tienen presentes en sus estructuras las farmacias, poder presentar con una retroalimentación las actividades básicas que se puedan desarrollar, con el fin de utilizar la RSE como una herramienta que nos lleve a una competitividad farmacéutica. Para lograr lo propuesto el presente trabajo se estructura en seis partes en introducción, historia y conceptos de RSE, Stakeholder, competitividad, metodología de investigación, resultados y conclusiones.

\section{Referencial teórico}

\section{La responsabilidad social en la historia}

Para poder abordar el tema de responsabilidad social empresarial en farmacia, se realizará un recuento por la historia, para tener claro las ideas evolutivas de la misma e 
ir definiendo algunos conceptos que se detallan a continuación. Dentro de responsabilidad social las primeras investigaciones datan en Estados Unidos a finales de los años 50 y principios de los 60 , todo se da al finalizar la segunda guerra mundial y otros conflictos mundiales como los de Vietnam (Schwalb \& García, 2003), despertando la inquietud de si con los trabajos de las empresas y la compra de insumos se seguía contribuyendo a mantener gobiernos y políticas económicas que ya se empezaban a censurar por ir en contra del interés colectivo o de derechos humanos. Al evaluar el impacto que pueden llegar a tener las empresas más cercanas se pide hacer una mayor revisión, dando inicio así a la responsabilidad social, como algo sostenible en el tiempo hasta la actualidad (Cantú-Martínez, 2013).

Con lo antes expuesto para estos años empiezan a tener participación voluntaria por parte de algunas organizaciones en la comunidad realizando actividades filantrópicas, aunque siendo puntuales. De a poco se fue evidenciando la verdadera capacidad que tenían las empresas privadas para con su capital ir contribuyendo a solucionar los problemas sociales, empezando por reconocer los daños y peligros que sus actividades podrían generar en el lugar que operan; Esto indirectamente fue generando una presión para que el estado vea la hora de intervenir, en su función de imponer normas para que se protejan los intereses públicos y naturales (Bowen, 2013).

En los años 60, empiezan a tener reuniones multisectoriales entre empresas, organizaciones y el gobierno. Con el fin de encontrar un equilibrio frente al cambio social, mencionar que inicialmente fue el estado quien, obligaba a cumplir normas y de a poco se iban sensibilizando las empresas. De tal modo que en la actualidad se han cambiado sus papeles originales (Castillo-Mejía, 2017).

Finalmente, en historia se puede tener en cuenta que pasó de ser una filantropía en la que se entrega un cheque por fuerza de una ley que lo obliga, a una relación más estrecha entre empresas y las organizaciones no gubernamentales pensando en cómo pueden interactuar para dar un valor agregado a la producción y que impacto positivo se puede 
Revista Arbitrada Interdisciplinaria KOINONIA

Año 2020. Vol V. N³. Especial: Administración

Hecho el depósito de Ley: FA2016000010 ISSN: $2542-3088$

FUNDACIÓN KOINONIA (F.K). Santa Ana de Coro. Venezuela.

José Humberto Picón-Lucero; Moisés Marcelo Matovelle-Romo; Flor Isabel Salazar-Vásquez

Ana Luisa del Rocío Ordoñez-Laso

dar en las comunidades más cercanas (Correa-Jaramillo, 2007).

\section{Responsabilidad social en Ecuador}

La Constitución Política del Ecuador reformada en el año 2008, impulsó un régimen de desarrollo basado en las directrices del buen vivir, que indica un sistema económico sostenible, justo, y respetuoso hacia la naturaleza, así como también vela para mejorar los niveles de vida de la comunidad. Sin embargo, en la constitución no define mecanismos alineados al incentivo y control de la responsabilidad social empresarial debido a que no hay ninguna determinación del concepto en el texto sobre las empresas socialmente responsable (Villacís-Laínez, et al., 2016). Por otro lado, para el año 2012, (Ortiz-Criollo, 2017) reseña la existencia de organizaciones promotoras de la RSE en el país tales como IDE Business School, Fundación AVINA, Cooperación Alemana al Desarrollo de Negocios, Cámara de Comercio Ecuatoriana-Americana, y el Ministerio de Coordinación de la Producción, Empleo y Competitividad. Mismas que realizaron un estudio sobre la perspectiva de la responsabilidad social en los negocios.

En el año 2017 con la última información trabajada por el gobierno nacional, la agenda de la RSE ha empezado a ganar importancia, en gran parte por las políticas tomadas desde el estado, lo cual ha ido generando un interés de empresarios, organizaciones y sociedad civil. Dentro del avance se puede evidenciar varios congresos, talleres de debate, empresas que ofrecen servicios profesionales de consultoría y reportes de sostenibilidad (Piedra, et al., 2018).

Por su parte, la reconocida firma auditora, (Deloitte, 2017), mediante su informe anual de Percepción de la Responsabilidad Corporativa y Sostenibilidad revela la postura del empresario en materia de RSE, mediante las encuestas efectuadas y analizadas en el periodo julio agosto del año en curso. Participaron 62 empresarios de organizaciones ecuatorianas quienes afirmaron en un $66 \%$ que la responsabilidad corporativa está ligada como consecuencia al rendimiento económico y financiero de la organización con un 
efecto multiplicador del valor agregado, buena reputación y atención por parte del mercado y bienestar hacia sus stakeholders.

Las empresas partícipes de esta observación atienden en un $21 \%$ como público de mayor dedicación e interés a sus colaboradores, dejando como último plano, las relaciones con los proveedores. Los consultados de la encuesta en mención, indicaron que la sostenibilidad organizacional está siendo administrada en un $55 \%$ con el apoyo de la alta dirección, teniendo la responsabilidad la gerencia general con un decrecimiento de 6 puntos frente al año 2013.

De acuerdo a (Kowszyk, et al., 2019), Ecuador forma parte de la red de mapeo de organizaciones promotoras de RSE de América Latina con 40 organizaciones conformadas en su mayoría por las asociaciones civiles y las organizaciones empresariales para fomentarla RSE en el medio. La red de mapeo de promotores de RSE en América Latina, tiene una herramienta digital de fácil acceso y de manera gratuita mediante su sitio web para utilidad del público en general, contando con la participación de organismos que se encargan de la formación, divulgación, capacitación, asesoramiento e incentivo de la temática. La intervención de las instituciones que están enmarcadas en el desarrollo de la RSE tiene una gran responsabilidad y desafío por cumplir frente a las carencias sociales que existen como son la desigualdad, la corrupción, el desempleo, los problemas ambientales y la pobreza.

Concepto responsabilidad Social (RS) se define como la encargada de identificar y encontrar soluciones a los problemas de interés colectivos tales como: medioambiente, condiciones de pobreza, salud, desigualdades, desnutrición y otros. En las que se vinculan activamente todos los actores, para emprender acciones que generen impactos positivos en la sociedad (Viteri-Moya, 2010). 
Concepto responsabilidad Social Empresarial (RSE) está ligado al interés de los empresarios o grupos comerciales en conservar una conexión con la sociedad y el medioambiente, en las que prevalece las bases éticas. También en la actualidad se ve a RSE como una estrategia para penetrar en los mercados y como la necesidad de mantener una legitimidad de la producción, que sea amigable con todos los actores de la sociedad a mediano y largo plazo. Es así que se puede definir la RSE como el medio para contribuir con la sociedad mejorando la credibilidad de una empresa y su competitividad. En la actualidad se evoca a que todas las empresas apliquen responsabilidad social empresarial viendo como una inversión para ganar prestigio en los mercados comerciales (Pérez-Espinoza, et al., 2016).

\section{Ventajas que dan a una farmacia aplicar responsabilidad social empresarial}

La RSE pasó de ser una actitud filantrópica de las empresas para convertirse en una oportunidad de mejora siendo un elemento distintivo y una ventaja competitiva, que a su vez entrega a una empresa una serie de beneficios como mejores oportunidades de negocios, mayor proyección y reconocimiento por parte del mercado. Lo que se verá repercutido en múltiples ventajas para los trabajadores y la sociedad en general. No ser responsable es muy peligroso para la rentabilidad, violar el medioambiente, no cumplir con las normas sociales y laborales es un gran problema inicialmente para empresas que tienen marcas conocidas y punteras, para luego pasar a las empresas que situaciones muy delicadas (Aguilera-Castro \& Puerto-Becerra, 2012).

Es así que la aplicación de la RSE se verá reflejada de forma casi inmediata mejorando la productividad y eficiencia. Estos beneficios son internos y externos que los clasificaremos como lo menciona (Chaves-Ávila \& Monzón-Campos, 2018).

1. Mayor permanencia de los empleados. Cuando existe un compromiso social también facilita el reclutamiento del personal y retención del talento pues los empleados se identifican con la misión y visión responsable de la empresa 
sintiéndose a gusto con el comportamiento de la misma. Acciones como motivar, acompañar y ayudar en momentos difíciles dentro y fuera de la empresa. Logra estimular la permanencia de los colaboradores el mayor periodo posible en su empleo, dándole un valor agregado

2. Lealtad del consumidor. Cada vez se evidencia de mejor manera la confianza y admiración por parte de los consumidores a las empresas que valoran a sus empleados, desarrollan proyectos sociales y se preocupan por el cuidado del medioambiente lo que garantiza su fidelidad.

3. Imagen de la marca. La RSE consolida las buenas prácticas dentro de la empresa nos genera un valor agregado a los negocios que es un potencial diferenciador para las estrategias de negocios, y tener ventaja competitiva respecto a otras empresas en el momento de llegar a los grupos de interés.

4. Sostenibilidad del negocio. Como se indicó los consumidores optan por las empresas socialmente responsables, con esa consideración las empresas que se basen en la aplicación de la RSE tendrán buenos resultados que se ven reflejados en las utilidades de la empresa.

5. Facilidad para obtener capital. Tanto del lado público y privado en la actualidad todas las empresas son evaluadas según sus prácticas de RSE, para ser adjudicatarias de productos financieros y recibir nuevas inversiones.

Con los elementos anteriores podemos indicar, que la responsabilidad social ayuda en la reducción de costos operativos, aporta a mejorar la imagen de la empresa en el mercado, genera mayor identidad y sentido de pertenencia de los empleados. Que lo convierte en el mejor negocio con visión para el futuro. Teniendo en cuenta lo mencionado por (Guismera \& Vaquero, 2000) concluyen que las empresas son éticas porque es rentable serlo. 


\section{Los stakeholders en la responsabilidad social empresarial farmacéutica}

Para poder aplicar en una forma amplia la RSE farmacéutica, debemos recordar que al igual que todas las empresas, comercializamos un bien para obtener un lucro. Esto lleva a que tengamos actividades de personas para personas, por medio de personas. Los Stakesholders son una base primordial dentro de la responsabilidad social, para llegar a cumplir el bien común de la comunidad basándose en actividades que genera la empresa. (Carreño-Godoy, 2020).

Lo mencionado nos lleva a definir como una empresa socialmente responsable a quienes les colocan en primer lugar a las personas con quienes se relaciona y toma decisiones para crear una propuesta de valor para todas ellas. A este grupo de personas se les conoce como Stakeholders que es un término en inglés que se popularizó gracias al filósofo (Edward Freeman, 2010), en su libro Strategic Management, en dicho texto con el término hace referencia a las personas que pueden ser afectados de manera positiva o negativa por las acciones de la empresa, ya sea con empleados, competidores, clientes, proveedores o dentro del medio que se desenvuelve (Rivera-Rodríguez \& Malaver-Rojas, 2011). En los grupos de interés podemos encontrar varios tipos, que se mencionan a continuación:

1. Propietarios y accionistas. Personas naturales o jurídicas que aportan con acciones, bienes o servicios para una empresa, buscan conseguir varios objetivos rentabilidad, económicamente rentable, socialmente responsable y ambientalmente sostenible. Un propietario está directamente involucrado en la empresa tiene influencia y poder, mientras un accionista su fuerza está en la junta directiva. En ambos casos se benefician de su éxito o se afectan por las pérdidas (Dopico-Parada, et al., 2012).

2. Empleados. Son la principal fuerza de una empresa, deben tener un contrato laboral, opción a formar sindicatos, ser escuchados, respetar sus derechos de salud y seguridad. Parte del éxito es que ellos comprendan y compartan los valores de la institución hacia la sociedad mediante palabras y acciones (Vallecillo-Gámez, et al., 
Revista Arbitrada Interdisciplinaria KOINONIA

Año 2020. Vol V. N³. Especial: Administración

Hecho el depósito de Ley: FA2016000010 ISSN: $2542-3088$

FUNDACIÓN KOINONIA (F.K). Santa Ana de Coro. Venezuela.

José Humberto Picón-Lucero; Moisés Marcelo Matovelle-Romo; Flor Isabel Salazar-Vásquez

Ana Luisa del Rocío Ordoñez-Laso

2016).

3. Clientes. Es el grupo humano que compra o contrata los servicios de una empresa son todos aquellos que compran o consumen el bien comercializado por la empresa. En RSE la institución debería estar interesada en ellos, así como ellos están interesados en la empresa. Existen dos tipos de clientes, los potenciales que se convertirán en nuestro público objetivo, y actuales que son parte de nuestros planes de negocio (Rodríguez-Gutiérrez, et al., 2013).

4. Distribuidores y socios comerciales. Facilitan la penetración de la empresa en el mercado, su labor es acercar nuestros productos o servicios a los clientes, tanto compradores como consumidores. Siempre se debe comulgar la misma ética comercial y la cadena de valor entre la empresa y este grupo de stakeholder para no dañar la imagen social (Morán, et al., 2016).

5. Proveedores. En el análisis de Guerrera (2009), dentro de este grupo de interés, se encuentran los profesionales o empresas que nos proporcionan material para nuestra infraestructura e insumo para poder ofertar a nuestros clientes. Es importante mantener relaciones de negocios estables y duraderos indicando siempre la política general de la empresa.

6. Competidores. Es un grupo de interés externo que ofrece productos iguales a los de la empresa buscando llegar al mismo grupo de clientes. Si el insumo que ellos comercializan es exactamente igual al ofrecido por la empresa y con las mismas características, se le puede considerar un competidor directo; Si ofrecen condiciones diferentes es un competidor indirecto (López \& Victoria-Mazuera, 2018).

7. Agentes sociales: Personas u organizaciones tales como sindicatos, asociación de consumidores, organizaciones no gubernamentales. Con su opinión de las empresas pueden determinar directamente en la decisión de consumo de los clientes, y para la empresa será determinante realizar una gestión favorable para mantener una buena imagen (Aguilera \& Puerto, 2012). 
8. Administraciones públicas. Dentro de este grupo encontramos a personas que ejercen un rol público, así como las instancias del estado, ejercen regulación a nivel local, nacional e internacional; marcando las políticas públicas que regirán a las empresas, otorgando derechos y obligaciones que en caso de no cumplimiento harán cumplir las normativas (Melle-Hernández, 2007)

9. Comunidad local. Categorizadas dentro de este grupo a todas las personas y organizaciones que se afectan directa o indirectamente por la actividad que desempeña la empresa. Así, una empresa farmacéutica tendrá en la comunidad de consumidores un stakeholder clave, una empresa de extracción minera tendrán a la comunidad que conforman organizaciones por el cuidado del medioambiente (Passos \& Spers, 2019).

10. Público en general. Conformada por todas aquellas organizaciones o consumidores en general, sin que tengan una relación directa con la empresa pero que pueden influir positiva o negativamente, por medio de sus comentarios vertidos a la sociedad. Así lo indica (Sanz-Hernández, 2019), como empresa podemos tener en cuenta aspectos clave como salud, medioambiente, ética comercial.

\section{La competitividad ligada a la responsabilidad social empresarial}

En la actualidad es importante tener en cuenta que la competitividad empresarial es un tema de trascendencia dentro de los sectores económicos que se encuentran dentro de países desarrollados o en vías de desarrollo. Para que una empresa llegue a globalizarse, se necesita que sea eficiente y eficaz para manejar los recursos financieros, humanos, tecnológicos y naturales; de esa manera se podrá dar frente a la competencia dentro y fuera del país (Hernández \& Bonomie, 2010).

Existen numerosas definiciones de competitividad, yendo desde el nivel de empresa hasta nivel de país, en todos los casos se indica que es el conjunto de acciones para mantenerse en el medio o mercado. Llevando a términos económicos se define como la 
capacidad de una persona, empresa o país para generar rentabilidad teniendo como referencia a los competidores. Para ello es importante buscar mejores condiciones entre precio, calidad, y oportunidad. Localmente se considera competitiva a una empresa que mantiene de forma creciente sus indicadores por medio de mejoras continuas en el uso de sus recursos.

En términos internacionales se considera competitiva a una empresa que es capaz de mantenerse en su medio sin tener en cuenta las protecciones o subsidios (NarváezMuñiz, et al., 2018). Desde el punto de vista económico la calidad de vida de un país es cada vez más dependiente de la competitividad de sus empresas, determinando si serán capaces de generar bienes o servicios a partir de los recursos que brinda la economía internacional, de hecho dentro del contexto mundial la competencia es cada vez más feroz que en años anteriores, obligando a que las empresas utilicen de mejor manera sus recursos para buscar menores costos de movilización, comunicativos, aranceles menores y difusión de herramientas tecnológicas. Siendo de esa manera más competitivas fuera de su territorio (Blanco-Rengel, 2014).

Dimensiones de la competitividad. Con los adelantos actuales tanto tecnológicos como de accesibilidad, las personas eligen según la necesidad de entre una gran gama sus productos o servicios de acuerdo a los atributos que ofrecen las empresas, por ejemplo, el costo de producto, calidad, atención; Por ello las empresas buscan posicionarse como las mejores en el servicio que busca el cliente (Yauri-Santos, et al., 2020). Por su parte (Mora, et al., 2015) Prioriza las principales dimensiones en la forma que se indica a continuación:

1. Planeación estratégica. Las gerencias de las empresas deberían estar en capacidad de poder organizar un modelo de negocios, partiendo de los ejes fundamentales como son la misión, visión y causa, pasando a un plan de marketing, gestión de talento, que en conjunto ayudarán al crecimiento y 
sostenibilidad de la empresa.

2. Producción y operaciones. Es importante manejar de forma actualizada los procesos de producción, capacitaciones, certificaciones y uso de nuevas herramientas, pues de su aplicación dependerá que las empresas puedan responder en muy poco tiempo a los cambios de necesidades de los clientes o factores externos. De esa manera logrando que a mayor modernización mayor nivel de competitividad.

3. Aseguramiento de la calidad. En esta dimensión se debe determinar las líneas de actividades planificadas y sistemáticas que nos lleven a tener normas de calidad, equipos de trabajo, certificaciones, planes para enfrentar posibles problemas. Estos parámetros deben ser demostrables con el fin de brindar la confianza necesaria a los clientes y proveedores.

4. Comercialización. Este elemento estratégico es tratado con mucha relevancia al tener una interacción directa con proveedores y clientes, pues se pone en marcha las acciones estructuradas y planeadas tales como; dar a conocer un nuevo producto, rutas de distribución, formas de pago, aumentar las ventas, satisfacción del cliente, conseguir mejores condiciones de los proveedores.

5. contabilidad y finanzas. Para lograr ser competitivos las empresas deberán tener definido su centro de costos, proyección y margen de ganancias, equipo de administración financiera monitoreando ventas, etc. El éxito o fracaso de las empresas está ligado en gran parte a sus finanzas pues determinará el acceso al financiamiento y la forma correcta de utilizar los recursos.

6. Recursos humanos. Teniendo en cuenta que sin seres humanos no existiría una empresa. Es muy importante tener un documento que nos indique el proceso de selección y contratación, capacitación y adiestramiento, causas de deserción, ambiente laboral, compensaciones, y seguridad industrial.

7. Gestión Ambiental. Es un tema que ha ganado gran relevancia dentro de los 
consumidores. Las circunstancias obligan a una empresa a ser competitiva y responsable con el medioambiente. Para lograr ser competitivos se debe analizar los documentos en materia ambiental, crear y aplicar programas, manejo de desechos, reciclaje. Entre otras acciones.

8. Sistemas de información. En gran variedad de textos se ha documentado la evidencia para determinar que la tecnología es el mecanismo para llegar a mejorar la competitividad empresarial. las organizaciones que implementan las tecnologías de comunicación e información, deberán tener personas especializadas en el tema, sistematizar su difusión, y crear planes de contingencia. Con el fin de añadir valor agregado a sus productos o servicios, reducir costos de comercialización, estrechar vínculos con clientes y proveedores.

\section{Decisiones estratégicas}

El éxito o fracaso de las empresas estará determinado en cuanto consideren todas las dimensiones de la competitividad. Es necesario que las actividades se ejecuten de forma igualitaria, simultánea y sistemática; pues cada área contribuye a la competitividad global. Las empresas desarrollan las estrategias para permanecer a largo plazo en el mercado, considerando necesario saber la forma en la que se va a competir y que solo depende de ellos llegar al éxito. Con esa consideración se debe de trabajar siempre innovando para aperturar el mercado, dar la importancia al estudio de dirección de empresas, identificar las fortalezas de la organización para competir de forma eficaz permitiendo mejorar los procesos actuales y cómo se estructurará la organización de forma que fomente el trabajo en equipo. (Ibarra-Cisneros, et al., 2017). Por tanto la finalidad de la estrategia competitiva será que la empresa sea rentable y sustentable teniendo en cuenta las fuerzas que rigen la competencia del mercado.

\section{Medición de responsabilidad social empresarial como estrategia competitiva}


Al sistematizar las dimensiones y decisiones estratégicas. Las empresas vienen investigando y trabajando en un conjunto de acciones que encaminan a lograr una ventaja competitiva. Una de las acciones que se desarrollan y propondremos en la presente investigación es la utilización de indicadores de responsabilidad social empresarial. Partiendo de los documentos internacionales de la responsabilidad social. Que se indican en la siguiente tabla.

Tabla 1.

Acuerdos internacionales sobre responsabilidad social.

\begin{tabular}{ll}
\multicolumn{1}{c}{ Organización } & \multicolumn{1}{c}{ Contenido } \\
\hline Declaración de los derechos humanos & $\begin{array}{l}\text { No pensado como principios de RSE, } \\
\text { contiene } 30 \text { artículos que habla de un } \\
\text { comportamiento responsable. }\end{array}$ \\
Pacto Mundial de los derechos humanos & -Derechos humanos. \\
& -Normas laborales \\
& -Medioambiente \\
& -Lucha contra la corrupción \\
Organización Internacional del Trabajo & -Libertad de asociación y libertad sindical, \\
(OIT) & derecho de negociación colectiva. \\
& -Eliminación del trabajo forzoso u \\
& obligatorio. \\
& -Abolición del trabajo infantil. \\
& Eliminación de la discriminación en \\
& materia de empleo y ocupación. \\
& -Derechos humanos. \\
& -Prácticas Laborales. \\
& -Medioambiente. \\
ISO 26000 & -Prácticas conforme a la legislación. \\
& -Consumidores. \\
\end{tabular}


Global Reporting Iniciative (GRI)

\section{Fuente: Elaboración propia.}

Basado en las directrices anteriores varias organizaciones han desarrollado indicadores que nos ayudan a sistematizar todas las áreas de RSE. Por funcionalidad en la presente investigación se utilizará los indicadores del Instituto ETHOS, siendo una herramienta de uso gratuito que posibilita un auto diagnóstico de las empresas para incorporar la responsabilidad social en sus negocios, mediante la definición de estrategias, políticas, y procesos.

En función de lo planteado, el objetivo de la investigación fue analizar la Responsabilidad social empresarial para el desarrollo de la competitividad farmacéutica de la ciudad de Cuenca - Ecuador.

\section{METODOLOGÍA}

La investigación fue de tipo descriptiva con diseño de campo no experimental, basándose en describir los elementos que conforman la responsabilidad social con el fin de generar 
una herramienta que catapulte a la competitividad farmacéutica, siendo la muestra poblacional estuvo constituida por $\mathbf{2 8 0}$ personas ligadas al sector farmacéutico de la ciudad de Cuenca - Ecuador, a quienes se les aplicó encuesta mediante cuestionario de diversas opciones de respuestas, procesándose la información recopilada desde la estadística descriptiva.

\section{RESULTADOS}

Con los instrumentos de investigación dirigida al personal farmacéutico, se organizó y filtró la información en siete áreas de acuerdo con las preguntas planteadas en el cuestionario implementado dentro de la responsabilidad social, se obtuvieron los resultados que se detallan a continuación.

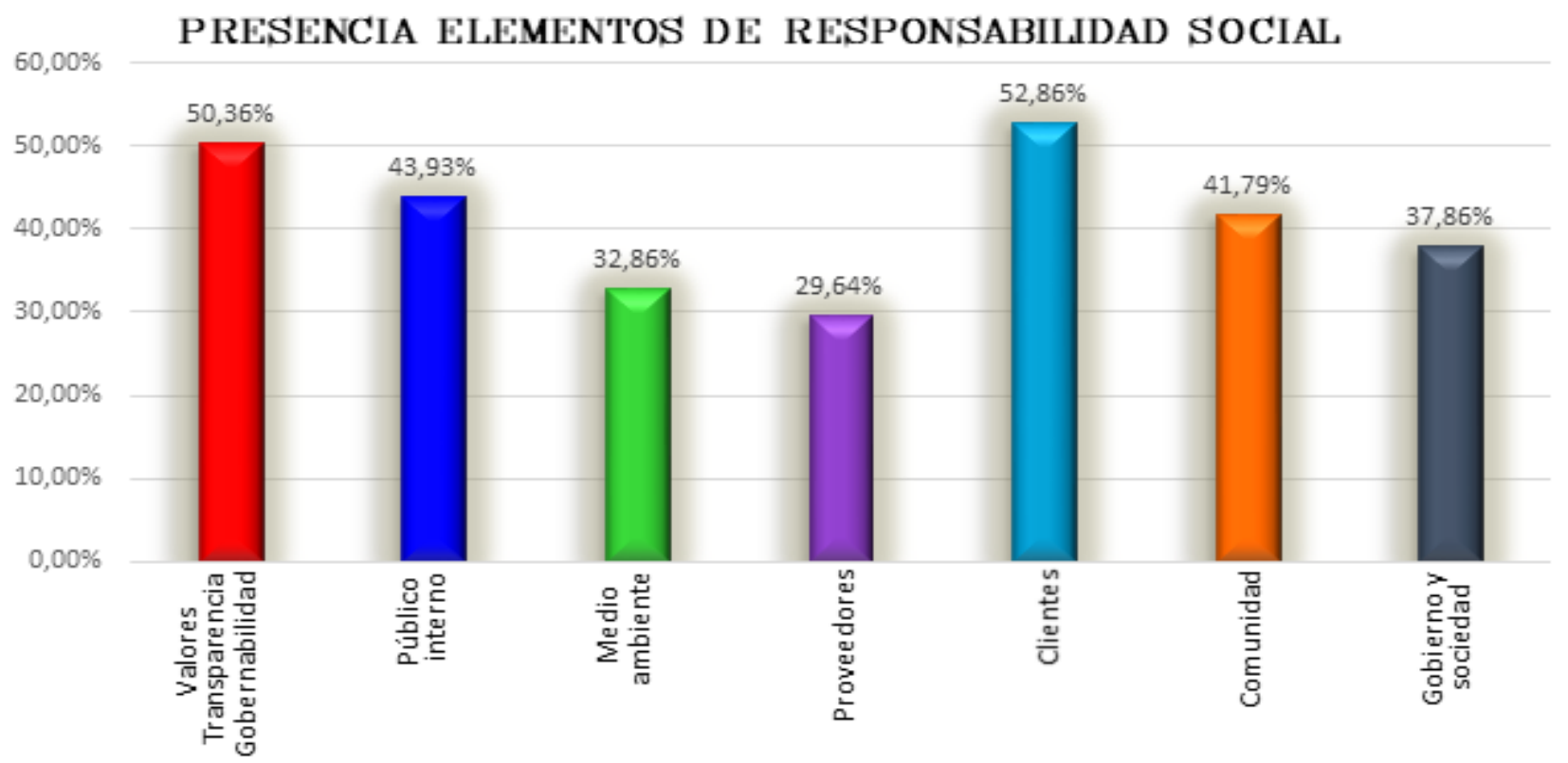

Figura 1. Actividades propuestas en la dimensión medio ambiente.

Fuente: Investigación de campo. 
Valores, Transparencia, Gobernabilidad: define todos los lineamientos que se debe tener en cuenta al estructurar una empresa, cumpliendo con los valores institucionales. El $50,36 \%$ de los encuestados perciben que en sus instituciones se aplica los elementos descritos en la encuesta, pero que están prestos a mejoras. El 49,64\% de los encuestados indica que en la farmacia que labora no se cuenta con un documento que indique los elementos institucionales.

Público interno: En este grupo de interés encontramos al contingente humano que brindan su fuerza laboral para mantener a flote las farmacias, dada su importancia la administración debe garantizar sus derechos, ofrecer seguridad y establecer sus obligaciones, así: $56,07 \%$ de encuestados coinciden que en su lugar de trabajo no se cumple con lo estipulado en este ítem. El 43,93\% indican que en las farmacias de labores, si cumple con los protocolos para poder brindar mayor seguridad a su público interno. Medio Ambiente: Es la interacción entre la farmacia y los efectos que puede tener hacia el planeta por el giro de negocio. El 67,14\% de los encuestados tienen una percepción de que estos elementos no se aplican en la farmacia o no sabe cómo aplicarlo. El 32,86\% de los encuestados indican que la empresa busca generar un impacto positivo en el medio ambiente y cuenta con los mecanismos para hacerlo.

Proveedores: Se basa en las personas o empresas que comercializan los insumos para el normal abastecimiento y funcionamiento de la farmacia. El 33,93\% de los encuestados coinciden que en sus farmacias no han estado interesados en dar una atención prioritaria a sus proveedores. El $29,64 \%$ de los encuestados indican que en las farmacias mantienen vínculos fuertes con sus proveedores les destinan el tiempo y el espacio necesario. El $36,43 \%$ de los encuestados menciona desconocer como es el tipo de relación que mantiene la farmacia con sus proveedores.

Consumidores y Clientes: En referencia a todas las personas que realizan algún tipo 
de adquisición en la farmacia, La información refleja que. El 52,86\% de encuestados considera que en la farmacia se brinda una correcta atención al cliente, interesándose por dar un seguimiento incluso posterior a su compra. El 47,14\% de los encuestados reconoce que no se le ha prestado la debida atención al cliente, descuidando escuchar sus sugerencias, reclamos y un servicio pos venta.

Comunidad: Es el espacio en el que se inserta la farmacia e interactúa con sus miembros, se debe lograr tener una excelente vinculación, la encuesta nos permitió recoger los siguientes datos. El 58,21\% de encuestados admite que existe un descuido en realizar actividades que permita vincular a la farmacia con la comunidad. El 41,79\% de encuestados por su parte indica que las farmacias son parte activa de la comunidad, ofreciendo programas de educación y salud, también patrocinan pasantías.

Gobierno y Sociedad: Es la relación que mantiene la farmacia con las instancias del gobierno para poder servir a la sociedad en general. El $62,14 \%$ de los encuestados manifiesta que se tenía desconocimiento de esta línea de acción, por lo que ha sido poco o nada desarrollada. El $37,86 \%$ de los encuestados indica que en la farmacia desarrolla acercamientos con las autoridades para propiciar escuelas de formación ciudadana, y de la misma forma propiciar becas para estudios. 


\section{PROPUESTA}

La propuesta en la presente investigación tiene como base la información recopilada en el análisis de los grupos de interés, con ello se propone desarrollar actividades de Responsabilidad Social Empresarial, teniendo en consideración las acciones mínimas dentro de las siete áreas identificadas para poder considerar a las farmacias del cantón Cuenca como socialmente responsable.

\section{RESPONSABILIDAD SOCIAL EMPRESARIAL}

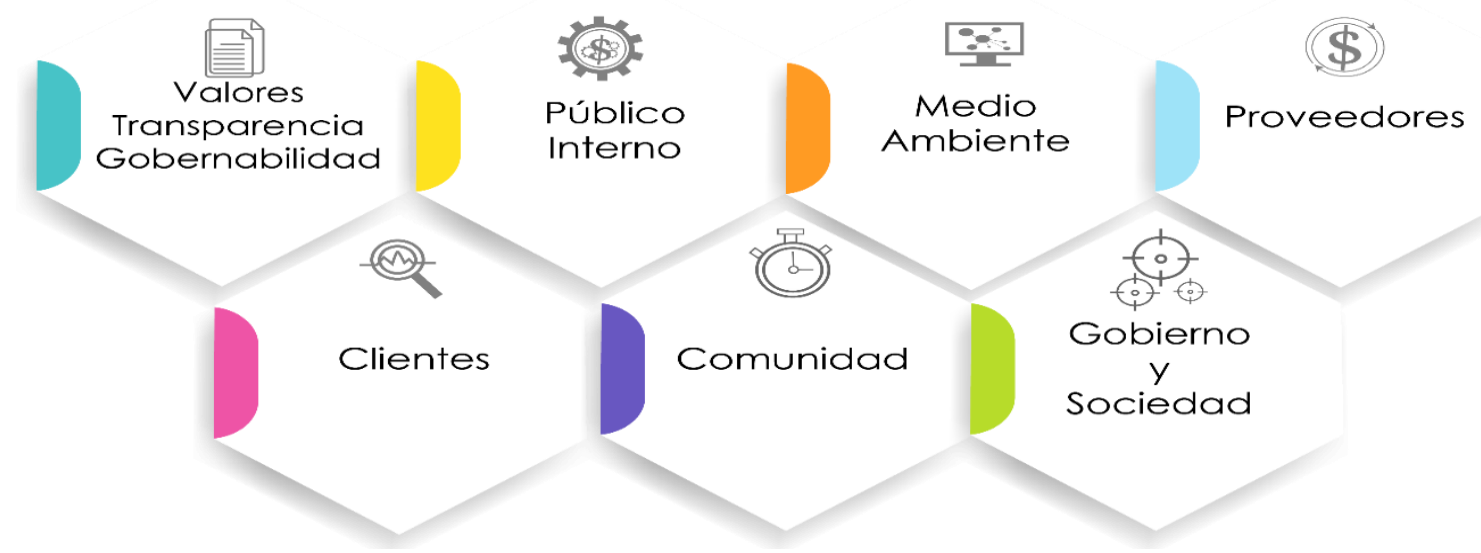

Figura 2: Propuesta áreas de responsabilidad social empresarial a desarrollar. Fuente: Investigación de campo. 


\section{Valores, Transparencia Y Gobernabilidad.}

La primera responsabilidad de una farmacia en RSE, es definir sus valores institucionales indicando su misión, visión causa; disponer de un código de ética, contar periódicamente con auditorías externas que permita transparentar sus actividades, y finalmente elaborar informes hacia sus accionistas garantizando que se está cumpliendo con el giro de negocio.

Construir valores instituciona les que permita una visión del futuro y perdurar en el tiempo.

Transparenta las actividades Económicas

Social

Ambiental

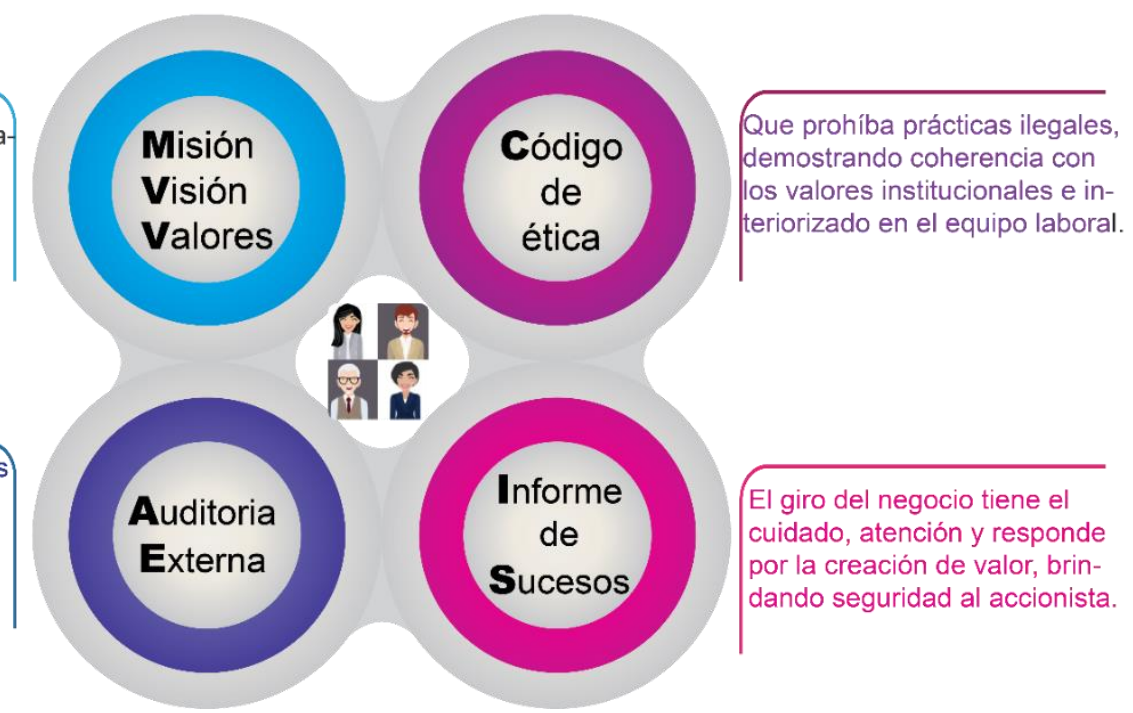

Figura 3: Actividades propuestas en la dimensión Valores, transparencia, gobernabilidad. Fuente: Investigación de campo. 


\section{Público interno.}

Considerando que son las personas quienes dan vida a la farmacia, se plantea contar con herramientas de escucha y evaluación, recoger las sugerencias para mejora, buscar los medios para brindar protección y seguridad, garantizar el respeto de los derechos de no discriminación y equidad de género, la incorporación de personas con discapacidad.

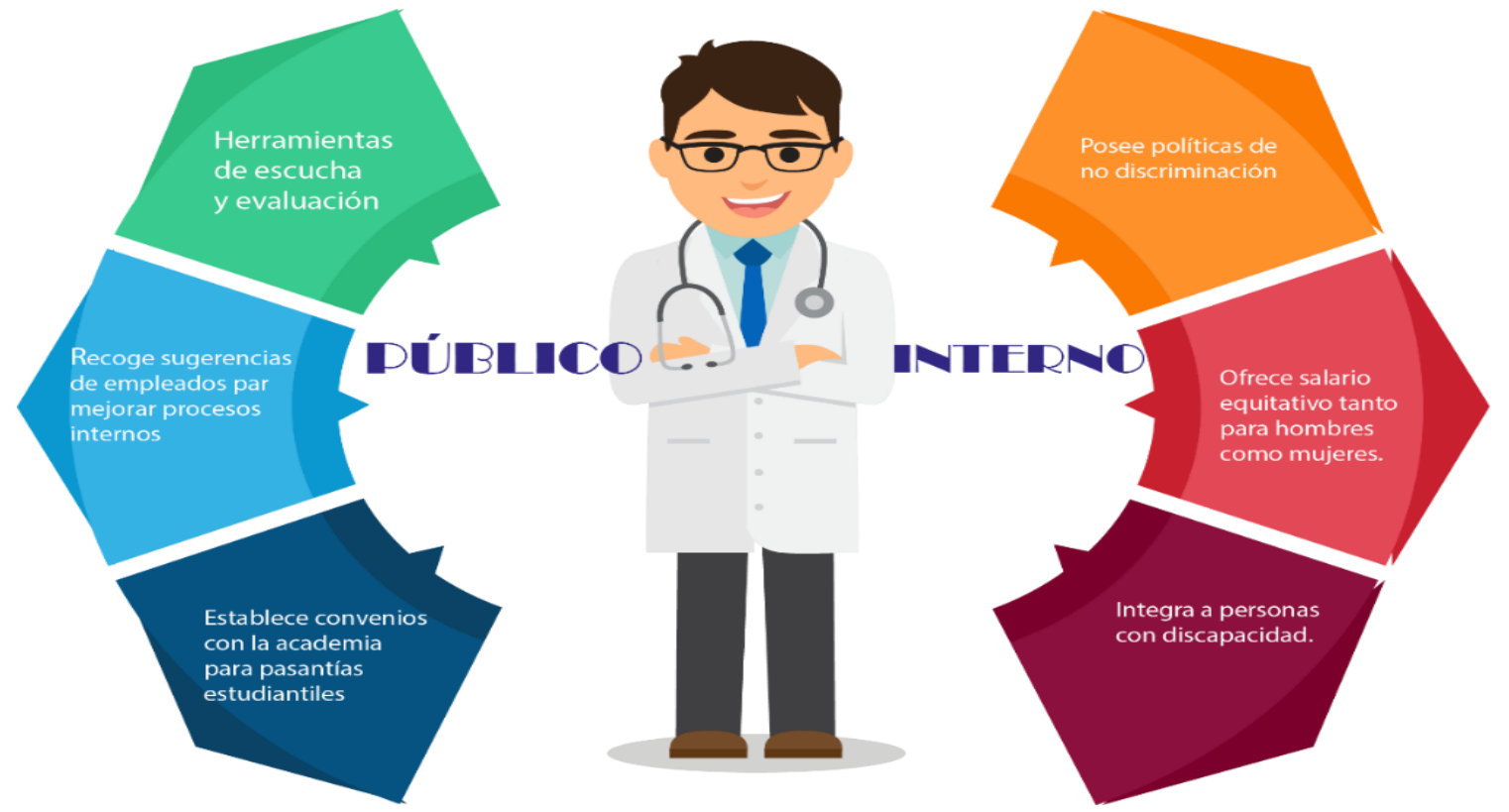

Figura 4: Actividades a desarrollar en la dimensión público interno.

Fuente: Investigación de campo. 


\section{Medio Ambiente.}

Se presenta actividades para disminuir los efectos del giro de negocio sobre el planeta, para el efecto se cuenta con personal que se encargue de esta área y pueda participar en comités locales ambientales, tener una política sobre el no consumo de material proveniente de explotación ilegal, mejorar la eficiencia energética, consumo consciente y reciclaje interno.

\section{Medio Ambiente}

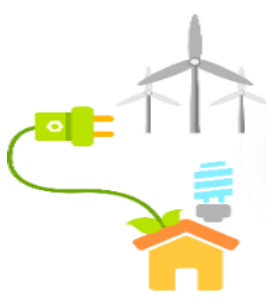

Participa en la construción de políticas de medio ambiente

Actividades de reciclaje que in volucren al barrio

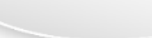

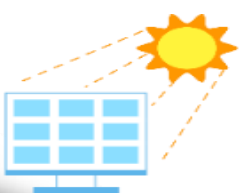

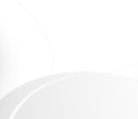

Campaña inter-

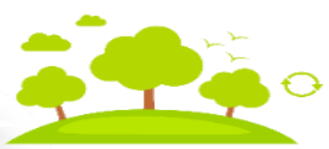
na para el uso eficiente de agua y energía

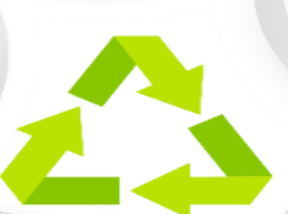

Implementación de actividades con organizaciones al cuidado de animales

Manejo adecuado de desechos en la farmacia

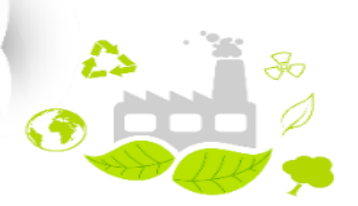

Figura 5: actividades propuestas en la dimensión medio ambiente.

Fuente: Investigación de campo. 
Revista Arbitrada Interdisciplinaria KOINONIA

Año 2020. Vol V. N³. Especial: Administración

Hecho el depósito de Ley: FA2016000010 ISSN: $2542-3088$

FUNDACIÓN KOINONIA (F.K). Santa Ana de Coro. Venezuela.

José Humberto Picón-Lucero; Moisés Marcelo Matovelle-Romo; Flor Isabel Salazar-Vásquez

Ana Luisa del Rocío Ordoñez-Laso

\section{Proveedores.}

La farmacia al no estar ligada a la producción de insumos, depende de proveedores, y dada la estrecha relación se debe conocer los elementos de responsabilidad social que ellos aplican, origen de su materia prima, tener una política de adquisiciones, para evitar productos falsos.

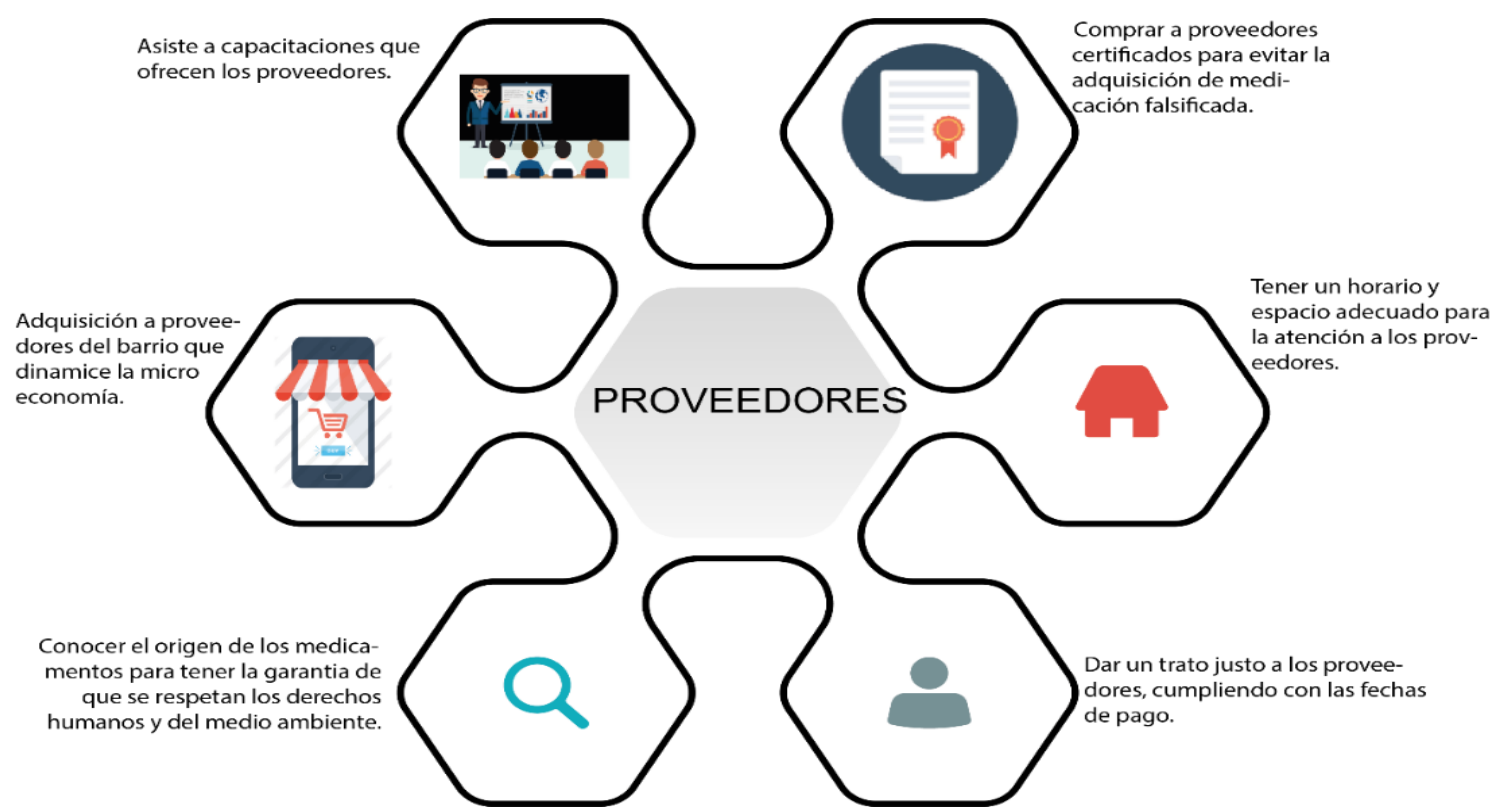

Figura 6: actividades propuestas en la dimensión proveedores.

Fuente: Investigación de campo. 


\section{Consumidores y Clientes.}

Para que exista una comercialización de medicamentos e insumos, necesitamos de personas que lo consuman, y para poder generar ese mercado en RSE se debe contar con personal calificado, evitar un material publicitario que denigre a los grupos de riesgo, contar con tecnología adecuada para mejorar el servicio en tiempo y calidad, generar convenios con aseguradoras.

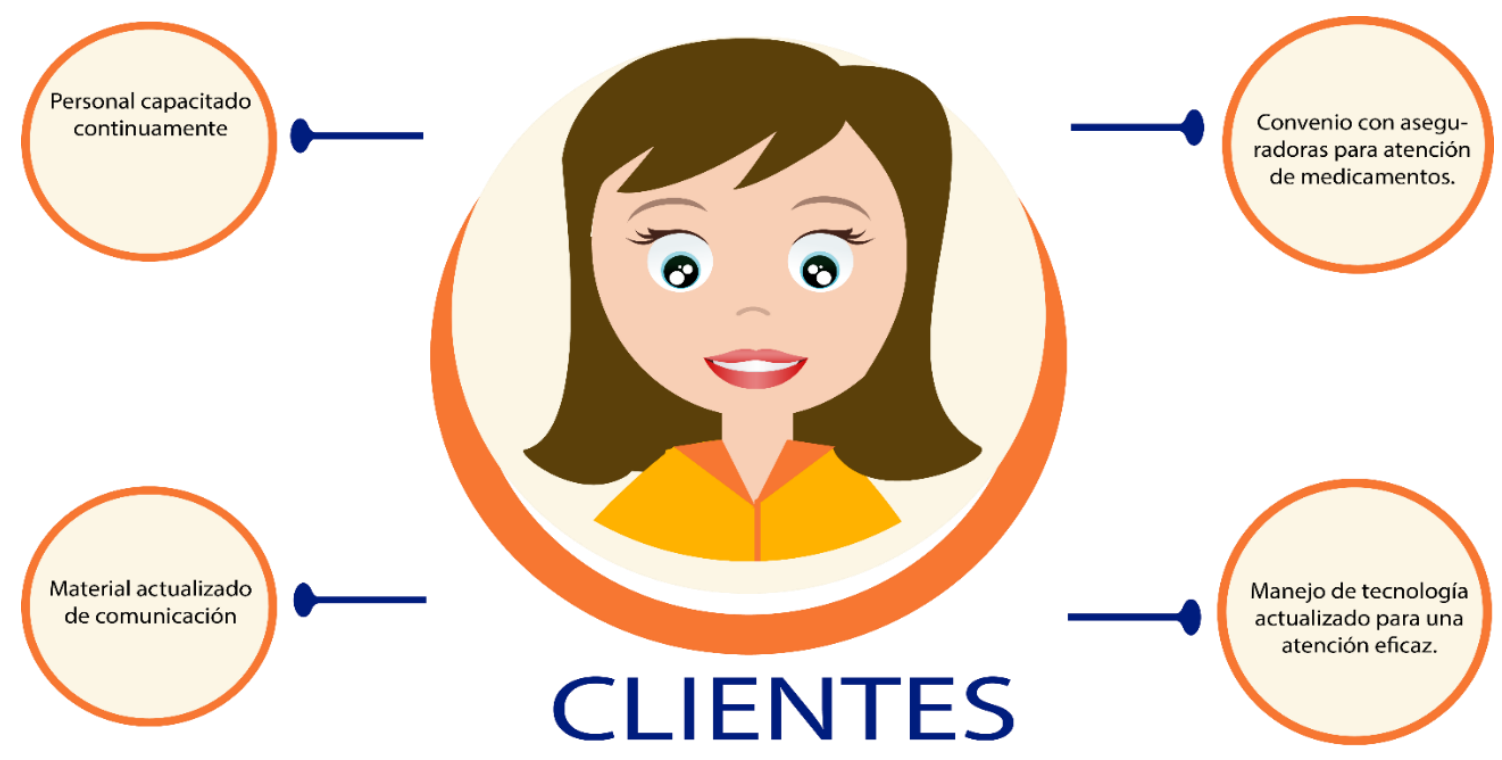

Figura 7: Actividades propuestas en la dimensión clientes.

Fuente: Investigación de campo. 


\section{Comunidad}

Encontramos acciones que se puede generar en pro de llevar una relación fraterna comunidad - farmacia, por ello es importante considerarla en la toma de decisiones, ser parte activa en identificar los problemas y la búsqueda de soluciones, respetar sus valores y tradiciones, ofrecer espacios de formación y campañas de salud.

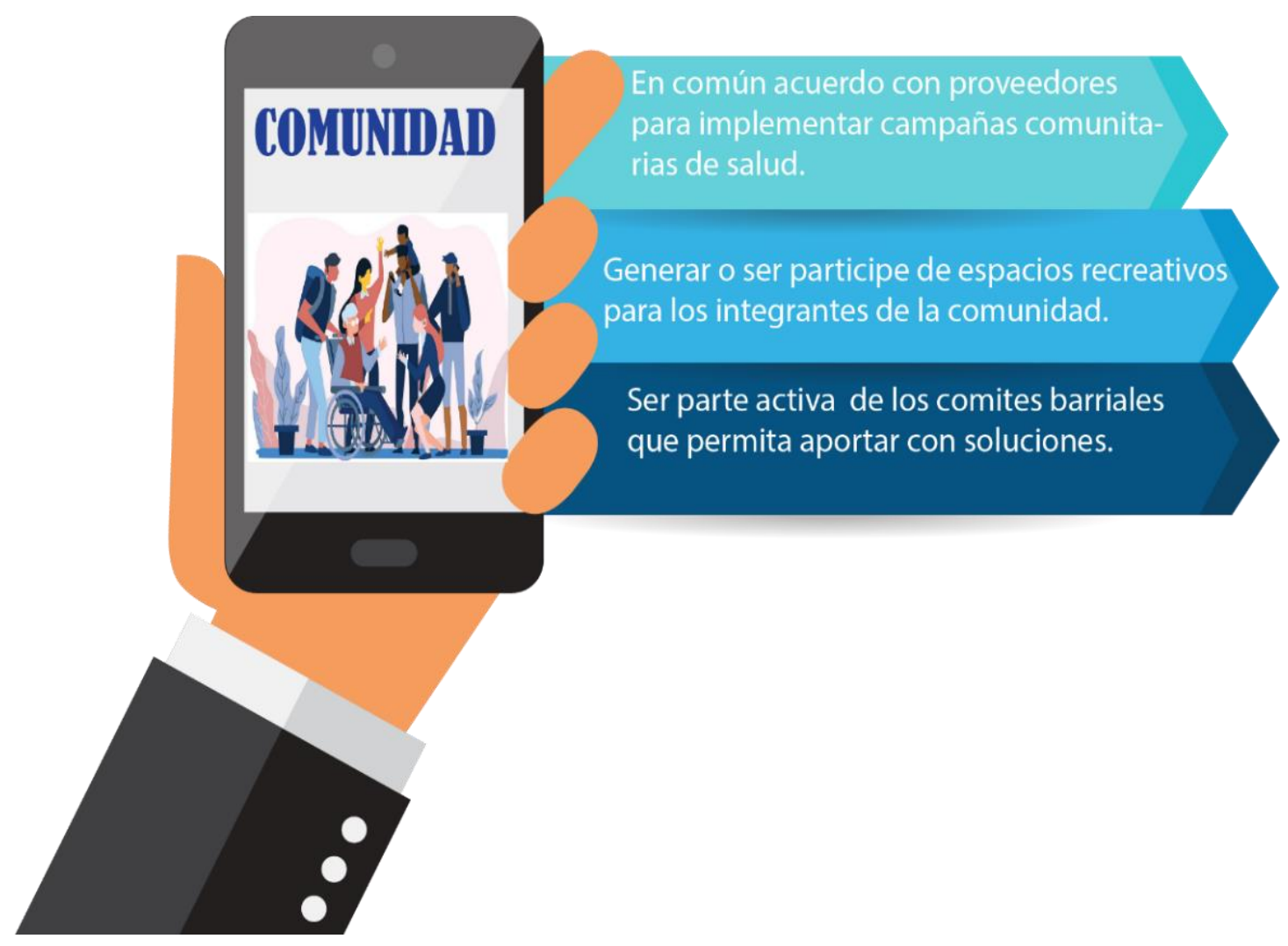

Figura 8: Actividades propuestas en la dimensión comunidad.

Fuente: Investigación de campo. 


\section{Gobierno y Sociedad.}

Las farmacias al encontrarse dentro del sector salud están íntimamente relacionado con el gobierno, cumpliendo normas y procedimientos, al cumplir con los compromisos, también se sirve a la sociedad, por ello se propone actividades como educación ciudadana, en participación y lucha contra la corrupción, promocionar o participar en campañas de interés público.

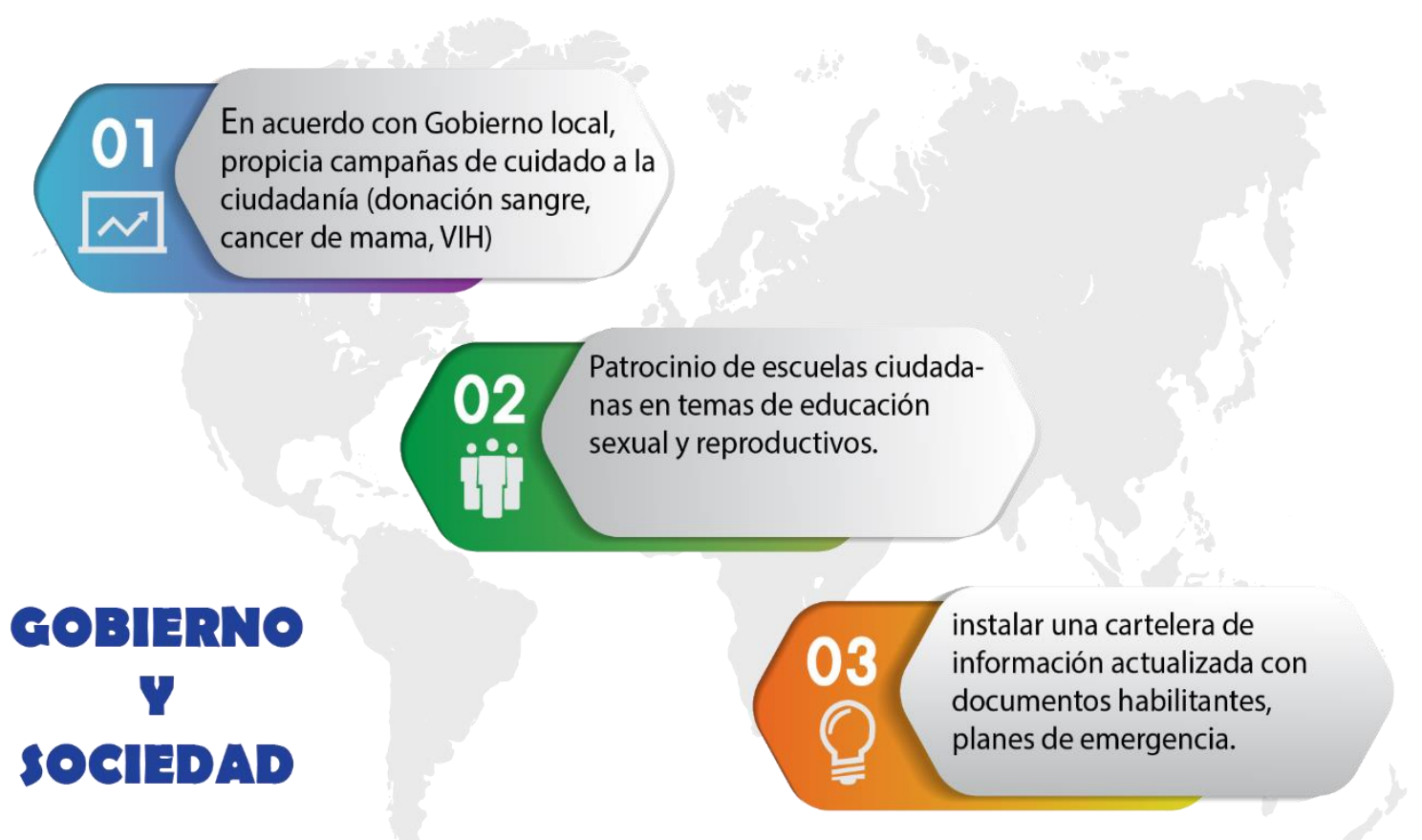

Figura 9: actividades propuestas en la dimensión gobierno y sociedad.

Fuente: Investigación de campo. 


\section{CONCLUSIONES}

Las farmacias juegan un rol muy importante dentro de la sociedad, siendo un vínculo directo entre los centros médicos y sus pacientes, están inmersas en pocas actividades de responsabilidad social, pero que no fueron consideradas como tal. El campo de acción para implementar la RSE, es amplio y van desde actividades de pronta ejecución hasta las que nos conlleva mayor tiempo de planificación, el implementar las acciones sugeridas, permitirá mejorar su legitimidad y ganar mayor confianza, aportando de forma efectiva a todos los stakeholders.

Con lo expuesto y aplicando sistemáticamente los elementos de RSE, es una herramienta válida para implementar la competitividad farmacéutica, es notorio el interés de los administradores por aplicar estos instrumentos, pues están conscientes que permitirá mejorar su imagen ante la sociedad.

\section{FINANCIAMIENTO}

No monetario.

\section{AGRADECIMIENTO}

Al personal farmacéutico por las facilidades brindadas para el desarrollo de la investigación. A la Universidad Católica de Cuenca por los conocimientos brindados.

\section{REFERENCIAS CONSULTADAS}

Aguilera, A., \& Puerto, D. (2012). Crecimiento empresarial basado en la responsabilidad social. [Business growth based on Social Responsibility]. Recuperado de: https://n9.cl/9smbw. 4-6. 
Aguilera-Castro, A., \& Puerto-Becerra, D. (2012). Crecimiento empresarial basado en la Responsabilidad Social. [Business growth based on Social Responsibility]. Pensamiento \& Gestión, (32), 1-26.

Alcántara-Moreno, G. (2008). La definición de salud de la Organización Mundial de la Salud y la interdisciplinariedad. [The definition of health of the World Health Organization and interdisciplinarity]. Sapiens Revista Universitaria de Investigación, 9(1),93-107.

Arcsa. (2020). Turnos de farmacias 2020 [Pharmacy shifts 2020]. Recuperado de https://n9.cl/cam8q

Blanco-Rangel, I. (2014). Sector Privado Entre la Responsabilidad Social y la Cooperación para el Desarrollo [Private Sector Between Social Responsibility and Cooperation for Development]. Ingeniare, (16), 79-93. https://doi.org/10.18041/1909-2458/ingeniare.16.593

Bowen, P. (2013). Foreword to the New Edition. In Bowen H. \& Gond J. (Authors), Social Responsibilities of the Businessman (pp. Vii-Viii). lowa City: University of lowa Press. Recuperado de https://n9.cl/h5eit

Cantú-Martínez, P. (2013). Responsabilidad Social Empresarial en el marco de la sustentabilidad [Corporate Social Responsibility within the framework of sustainability]. Economía Y Sociedad, 18(44), 21-33.

Carreño-Godoy, M. J., Erazo-Álvarez, J. C., Narváez-Zurita, C. I., \& Moreno, V. P. (2020). La responsabilidad social en las empresas camaroneras. [Social responsibility in shrimp companies]. Revista Arbitrada Interdisciplinaria Koinonía, 5(10), 455-482. http://dx.doi.org/10.35381/r.k.v5i10.702

Castillo-Mejia, E. (2017). Teorías y Enfoques que Sustentan la Responsabilidad. [ Theories and Approaches Underpinning Responsibility]. Tesis en Ingenieria en Contaduría Pública. Milagro, Ecuador: Universidad Estatal de Milagro. Recuperado de https://n9.cl/4owx.

Chaves-Ávila, R., \& Monzón-Campos, J. L. (2018). La economía social ante los paradigmas económicos emergentes: innovación social, economía colaborativa, economía circular, responsabilidad social empresarial, economía del bien común, empresa social y economía solidaria. [The social economy in the face of emerging 
economic paradigms: social innovation, collaborative economy, circular economy, corporate social responsibility, economy of the common good, social enterprise and solidarity economy]. Revista de Economica Pública, Social y Cooperativa, 93, 5-50 https://doi.org/10.7203/CIRIEC-E.93.12901

Chen, I., Srinidhi, B., Tsang, A, \& Yu, W. (2016). Audited financial reporting and voluntary disclosure of corporate social responsibility (CSR) reports. Journal of Management Accounting Research, 28 (2): 53-76. https://doi.org/10.2308/jmar-51411

Coronel-Carbo, J., \& Marzo-Páez, N. (2017). La promoción de la salud: evolución y retos en América Latina. [Health promotion: evolution and challenges in Latin America]. MEDISAN, 21(7), 926-932.

Correa-Jaramillo, J. G. (2007). Evolución histórica de los conceptos de responsabilidad social empresarial y balance social [Historical evolution of the concepts of corporate social responsibility and social balance]. Semestre Económico, 10(20), 87-102.

Cuadrado, B., García, R., \& Martínez, J. (2014). Efecto de la composición del consejo de administración en las prácticas de responsabilidad social corporativa[Effect of the composition of the board of directors on corporate social responsibility]. Revista de Contabilidad - Spanish Accounting Review, 18(1), 23-25. https://doi.org/10.1016/j.rcsar.2014.02.003

Del-Castillo, M., Penagos, J., \& Navarro, J. (2011). Estrategias Metodológicas para el Diseño e Implementación del Programa de Responsabilidad Social Empresarial en una Empresa del Sector Farmacéutico [Methodological Strategies for Design and Implementation of the Programs of Corporate Social Responsibility in a Pharmaceutical Company Sector]. Ingeniare, 6(11), 45-52.

Deloitte. (2017). Estudio de tendencias de Sostenibilidad. [Sustainability trends study]. Recuperado de https://n9.cl/dzil

Dopico-Parada, A., \& Rodríguez-Daponte, R., \& González-Vázquez, E. (2012). La responsabilidad social empresarial y los stakeholders: un análisis clúster [Corporate social responsibility and stakeholders: a cluster analysis]. Revista Galega de Economía, 21(1),1-17.

Freeman, E. (2010). Strategic management. En E. Freeman, Strategic management. (p. 43). New York: Cambridge university press. Recuperado de https://n9.cl/vauo 
Gismera, L., \& Vaquero, M. (2000). La responsabilidad social de las empresas en España: la acción social. [The social responsibility of companies in Spain: social action]. Papeles de Economía y Dirección, 5, 1-8.

Guerrera, F. (2009). Welch condemns share price focus. Recuperado de https://n9.cl//nkpm

Hernández, C., \& Bonomie, M. (2010). Responsabilidad Social Empresarial: Estrategia de competitividad en el marco de la globalización. [Corporate Social Responsibility: Competitiveness strategy in the framework of globalization]. Revista de Formación Gerencial, 9(1), 144-168.

Ibarra-Cisneros, M. A., González-Torres, L. A., \& Demuner-Flores, M. (2017). Competitividad empresarial de las pequeñas y medianas empresas manufactureras de Baja California. [Business competitiveness in the small and medium-sized enterprises of the manufacturing sector in Baja California]. Estudios Fronterizos, 18(35), 4-17. https://doi.org/10.21670/ref.2017.35.a06

Kermani, F. (2004). Generics Companies: Aspiring to Innovate. Journal of Generic Medicines, 1(4), 336-346.

Kowszyk, Y, Castro, M, Maher, R, \& Guidolín, A. (2019). Responsabilidad Social Empresarial y Objetivos de Desarrollo Sostenible en la Unión Europea, América Latina y el Caribe. Planes Nacionales de Acción y Políticas Públicas para promover la Sustentabilidad. [Corporate Social Responsibility and Sustainable Development Goals in the European Union, Latin America and the Caribbean. National Action Plans and Public Policies to promote Sustainability]. EU-LAC FOUNDATION. Recuperado de https://n9.cl/ydbzn

López, J., \& Victoria-Mazuera, J. (2018). Propuesta de un modelo de relación efectiva de los stakeholders. [Proposal for an effective stakeholder relationship model]. Recuperado de https://n9.cl/6bxt

Melle-Hernández, M. (2007). La responsabilidad social dentro del sector público. [Social responsibility within the public sector]. Ekonomiaz, 65(2), 84-107.

Molla, j. v. (2010). Responsabilidad social. [social responsability]. En j. v. molls, responsabilidad social (pág. 91). Quito: Alguila. 
Mora, E., Vera, M., \& Melgarejo, Z. (2015). Planificación estratégica y niveles de competitividad de las Mipymes del sector comercio en Bogotá. [Strategic planning and competitiveness levels of SMEs in the business sector in BogotáPlaneamento estratégico e níveis de competitividade das PMEs do sector do comércio em Bogotá]. Estudios gerenciales, 31(134), 79-87. https://doi.org/10.1016/j.estger.2014.08.001

Morán Montalvo, C., Rodríguez Valencia, L., Torres Olivo, M., Aguilar Parra, A., \& Villalta Borja, M. (junio de 2016). STAKEHOLDERS, RESPONSABILIDAD SOCIAL EN ECUADOR [Stakeholders, social responsibility in Ecuador.]. Revista Científica y Tecnológica UPSE, 22-24. https://doi.org/10.26423/rctu.v3i2.147

Morán, C., Rodríguez, L., Torres, M., Aguilar, A., \& Villalta, M. (2016). Stakeholders, responsabilidad social en Ecuador [Stakeholders, social responsibility in Ecuador]. Revista Científica Y Tecnológica UPSE, 3(2), 21-30. https://doi.org/10.26423/rctu.v3i2.147

Muñoz-Arias, J. (1952). Apuntes para la historia de la farmacia en el Ecuador. [Notes for the history of the pharmacy in Ecuador]. Quito: Editorial Rumiñahui.

Narváez-Muñiz, L., Avilez-Merino, R., \& Galeas-Guijarro, E. (2018). Estrategias y dimensiones competitivas de las empresas. Orientaciones metodológicas [Strategies and competitive dimensions of companies. Methodological guidelines]. Opuntia Brava, 10(4), 71-76.

Ortiz-Criollo, J. F. (2017). Análisis de la Responsabilidad Social y Sostenibilidad en Gestión Universitaria. Caso: Universidad técnica particular de Loja-Ecuador. [Analysis of Social Responsibility and Sustainability in University Management. Case: Private Technical University of Loja-Ecuador]. Ciencias Administrativas, (10), 009. https://doi.org/10.24215/23143738e009

Passos, C., \& Spers, R. (2019). Analysis of Intention and Practices of Collaboration with Stakeholders in Brazil. Revista Ibero-Americana de Estratégia (RIAE), 18(2), 171187. https://doi.org/10.5585/riae.v18i2.15157 
Pérez-Espinoza, M, Espinoza-Carrión, C, \& Peralta-Mocha, B. (2016). La responsabilidad social empresarial y su enfoque ambiental: una visión sostenible a futuro [Corporate social responsibility and environmentalapproach: a sustainable vision to the future]. Revista Universidad y Sociedad, 8(3), 169-178.

Piedra, A., Hinojosa, A., Guevara, M., \& Erazo, J. (2018). Responsabilidad social en las cooperativas de ahorro y crédito del Ecuador: una medición desde la web [Social responsibility in savings and credit cooperatives in Ecuador: a measurement from the web]. Telos, 21(3), 618-642. https://doi.org/10.36390/telos213.07

Porter, M., \& Kramer, M. (2006). Estrategia y sociedad [Strategy and society] Harvard Bussines Review, América Latina. Recuperado de https://n9.cl/s8q15

Rivera-Rodríguez, H. A., \& Malaver-Rojas, M. N. (2011). La organización: los stakeholders y la responsabilidad social [The organization: stakeholders and social responsibility]. Borradores de Investigación - Escuela de Administración, (97), 534.

Rodríguez-Gutiérrez, P., Fuentes-García, F. J., \& Sánchez-Cañizares, S. (2013). Revelación de información sobre clientes, comunidad, empleados y medioambiente en las entidades finacieras españolas a través de las memorias de la responsabilidad social coorporativa. [Disclosure of information about clients, the community, employees an]. Investigaciones Europeas de Dirección y Economía de la Empresa 19, 180-187. https://doi.org/10.1016/j.iedee.2012.12.002

Sanz-Hernández, A. (2019). Medios de comunicación y stakeholders: contribución al debate público de la pobreza y justicia energética en España. [Media and Stakeholders: Contribution to the Public Debate on Poverty and Energy Justice in Spain]. Revista Española de Investigaciones Sociologicas, 168, 73-92. http://dx.doi.org/10.5477/cis/reis. 168.73

Schwalb, M., \& Garcia, E. (2003). Evolución del compromiso social de las empresas: historia y enfoques [Evolution of the social commitment of companies: history and approaches]. Repositorio Universidad del pacífico. Recuperado de http://hdl.handle.net/11354/1035

Tafur-Valderrama, E., \& García-Jiménez, E. (2006). Aproximación del rol de farmacéutico en la calidad de vida relacionada con la salud. [Approach to the role of the pharmacist in health related quality of life]. Pharmacy Practice (Granada), 4(1), 1823. 
Revista Arbitrada Interdisciplinaria KOINONIA

Año 2020. Vol V. N³. Especial: Administración

Hecho el depósito de Ley: FA2016000010 ISSN: $2542-3088$

FUNDACIÓN KOINONIA (F.K). Santa Ana de Coro. Venezuela.

José Humberto Picón-Lucero; Moisés Marcelo Matovelle-Romo; Flor Isabel Salazar-Vásquez

Ana Luisa del Rocío Ordoñez-Laso

Vallecillo-Gámez, M., \& Gutiérrez-González, J. (2016). La responsabilidad social pública como elemento de política de empleo [Public social responsibility as an element of employment policy]. CIRIEC-España, Revista de Economía Pública, Social y Cooperativa, (87), 1-28.

Villacís-Laínez, C. A., Suarez-Núñez, Y. F., \& Güillín-Llanos, X. M. (2016). Análisis de la Responsabilidad Social en el Ecuador [Analysis of Social Responsibility in Ecuador]. Revista Publicando, 3(8), 452-466.

Viteri-Moya, J. (2010). Responsabilidad social. [Social responsability]. Enfoque UTE, 1(1), pp. 90 - 100. https://doi.org/10.29019/enfoqueute.v1n1.20

Yauri-Santos, G. M., Erazo-Álvarez, J. C., Narváez-Zurita, C. I., \& Moreno, V. P. (). Plan de responsabilidad social empresarial para el sector inmobiliario. [Corporate social responsibility plan for the real estate sector]. Revista Arbitrada Interdisciplinaria Koinonía, 5(10), 397-426. http://dx.doi.org/10.35381/r.k.v5i10.845 